\title{
Methods of Determining Lead Speciation in Fly Ash by X-ray Absorption Fine-Structure Spectroscopy and a Sequential Extraction Procedure
}

\author{
Atsushi Funatsuki, ${ }^{* \dagger}$ Masaki TaKaOKa, ${ }^{* *}$ Kazuyuki Oshita, ${ }^{* *}$ and Nobuo TAKedA ${ }^{* * *}$ \\ *Forensic Science Laboratory, Mie Prefectural Police H. Q., 1-100 Sakaemachi, Tsu, Mie 514-8514, Japan \\ **Department of Urban and Environmental Engineering, Graduate School of Engineering, Kyoto University, \\ Katsura, Nishikyo, Kyoto 615-8540, Japan \\ ***Ritsumeikan University Research Center for Eco-Technology, 1-1-1 Nojihigashi, Kusatsu, Shiga 525-8577, \\ Japan
}

\begin{abstract}
Understanding the chemical state of lead in fly ash generated from a waste thermal treatment is important, since the toxicity and solubility of the element depends on its chemical state. This study identified three potential methods for obtaining quantitative information regarding the chemical state of lead in fly ash: X-ray absorption near edge structure (XANES) analysis, extended X-ray absorption fine structure (EXAFS) analysis, and the sequential extraction procedure. The result of this procedure was strongly affected by the $\mathrm{pH}$ and sample matrix, and did not necessarily accurately reflect the chemical state. It was difficult to quantitatively examine the chemical species using only EXAFS. However, an XANES fitting enabled direct quantification of the chemical species. An XANES analysis showed that $\mathrm{PbSiO}_{3}, \mathrm{PbCl}_{2}$, or $\mathrm{Pb}_{2} \mathrm{O}(\mathrm{OH})_{2}$ was the predominant chemical species in fly ash. We concluded that multiple analyses should be compared multilaterally to improve the accuracy of the final analysis.
\end{abstract}

(Received December 15, 2011; Accepted March 26, 2012; Published May 10, 2012)

\section{Introduction}

In Japan, waste is processed by incineration or melting for the purpose of public sanitation and volume reduction. During these processes, organic matter is destroyed and inorganic residues form at high temperature. In general, municipal solid-waste incineration residue is classified as bottom ash, boiler ash, or fly ash. Of these, fly ash is collected during the processing of flue gas, and contains heavy metals concentrated during cooling of flue gas. The disposal of fly ash requires an intermediate treatment, such as a chemical treatment, to render heavy metals insoluble. Of the heavy metals contained in fly ash, lead is present in relatively high concentrations (up to tens of thousands of $\mathrm{mg} \mathrm{kg}^{-1}$ degree). Because of lead's toxicity, proper disposal of the treated fly ash is critical. It is also important to understand the chemical state of lead in order to store the treated material safely, since the behavior or mobility of lead in the environment depends on its chemical state.

X-ray diffraction (XRD), ${ }^{1,2} \mathrm{X}$-ray photoelectron spectroscopy (XPS), ${ }^{3-5} \mathrm{X}$-ray absorption fine structure (XAFS) spectroscopy, ${ }^{6-12}$ and a sequential extraction procedure ${ }^{1,12-16}$ have been used to determine the chemical speciation of heavy metals in ash. XRD and XPS have the advantage of being nondestructive methods. However, XRD is generally used to identify crystalline compounds, while XPS is a surface analysis method. Thus, it is difficult to determine the chemical speciation of heavy metals at

$\dagger$ To whom correspondence should be addressed.

E-mail: laboratory@ police.pref.mie.jp low concentrations in ash by these methods. The XAFS method is a more specialized technique, requiring an X-ray source and high-energy resolution, and is often carried out in synchrotron facilities. XAFS spectroscopy enables quantitative chemical speciation to be performed in dilute and chemically complex systems. In the sequential extraction procedure, a sample is added to an extraction reagent, and is then shaken, centrifuged, and filtered to obtain an extract solution; this process is performed repeatedly for each fraction. Thus, the sequential extraction procedure can be performed in a general laboratory. ${ }^{17}$ The sequential extraction procedure also allows for the analysis of heavy metals present at low concentrations by inductively coupled plasma (ICP) analysis. However, in performing the sequential extraction procedure, it is necessary to take account of the incomplete dissolution of target phases, the removal of non-target species, and the incomplete removal of dissolved metals due to re-adsorption on remaining components, or due to re-precipitation with the added reagent.

In the present study, we examined the quantitative determination of lead chemical species in 13 kinds of fly ash using three analytical methods: X-ray absorption near edge structure (XANES) analysis, extended X-ray absorption fine structure (EXAFS) analysis, and the sequential extraction procedure. The results of these analyses were examined statistically and compared multilaterally. Few studies have multilaterally estimated lead species in fly ash by combining multiple analyses. Herck et al. ${ }^{14}$ used a sequential extraction procedure and a chemical equilibrium model simulation; Abanades et al..$^{16}$ used a thermodynamic simulation, a sequential extraction procedure, and X-ray microanalysis. In this study, 
samples were collected from Japanese facilities that use general equipment and processes. Therefore, the outcomes of this study can be applied to general fly ash. To quantify the various lead species using the sequential extraction procedure, reference materials were first fractionated using the procedure, and the residues were analyzed by XANES and EXAFS analysis. In addition, based on the results obtained from composition analysis, sequential extraction procedure, and XAFS analysis, the chemical species of lead extracted in the sequential extraction procedure were estimated via simulation using a chemical equilibrium model calculation program (Visual MINTEQ).

\section{Experimental}

\section{Samples}

Six kinds of municipal solid waste incineration (MSWI) fly ash and seven kinds of molten fly ash were collected; both MSWI fly ash and molten fly ash are referred to here as "fly ash". Table 1 gives the specifications of the fly ash investigated in this study. Fly ashes A-E were MSWI fly ash collected

Table 1 Specifications of samples

\begin{tabular}{cllccc}
\hline Sample & Incinerator & Waste $^{\mathrm{a}}$ & $\begin{array}{c}\text { Dust } \\
\text { collectior }^{\mathrm{b}}\end{array}$ & Lime & $\begin{array}{c}\text { Activated } \\
\text { carbon }\end{array}$ \\
\hline A & Stoker fired & MSW & BF & + & \\
B & Stoker fired & MSW & BF & + & \\
C & Stoker fired & MSW & BF & + & \\
D & Stoker fired & MSW & EP & & \\
E & Stoker fired & MSW & EP & & + \\
F & Fluidized bed & MSW & BF & & \\
G & Shaft furnace & ASR & BF & + & + \\
& direct melting & & & & \\
H & Shaft furnace & BA, FA & BF & + & + \\
& direct melting & & & & \\
I & Burner melting & ASR & BF & + & + \\
J & Burner melting & BA & BF & + & \\
K & Plasma melting & FA & BF & + & \\
L & Plasma melting & BA & BF & + & + \\
M & Plasma melting & BA, FA & BF & + & + \\
\hline
\end{tabular}

a. MSW, Municipal solid waste; ASR, automobile shredded residue; BA, bottom ash; FA, fly ash.

b. BF, Bag filter; EP, electric precipitator. from stoker-type incinerators, while fly ash F was MSWI fly ash collected from a fluidized bed-type incinerator. Fly ashes $\mathrm{G}$ and $\mathrm{H}$ were molten fly ash collected from shaft-type furnace incinerators, fly ashes I and J were molten fly ash collected from surface melting furnace incinerators, and fly ashes $\mathrm{K}-\mathrm{M}$ were molten fly ash collected from plasma-type furnace incinerators. There were significant differences between the flue gas treatment systems; those producing fly ashes A - C and $\mathrm{G}-\mathrm{M}$ had lime processing, whereas those producing fly ashes $\mathrm{E}, \mathrm{G}-\mathrm{I}, \mathrm{L}$, and $\mathrm{M}$ had activated carbon processing.

\section{Characterization of fly ash}

The $\mathrm{Cl}, \mathrm{O}, \mathrm{S}$, and $\mathrm{Si}$ concentrations in fly ash were determined by X-ray fluorescence (XRF; Shimadzu, XRF-1700) spectroscopy using the fundamental parameter method. ${ }^{18}$ Other elements were measured by inductively coupled plasma-atomic emission spectrometry (ICP-AES). To $100 \mathrm{mg}$ of a sample, $5 \mathrm{ml}$ of hydrofluoric acid, $3 \mathrm{ml}$ of nitric acid, and $2 \mathrm{ml}$ of hydrochloric acid were added; samples were subsequently digested with a microwave digestion system (CRM, MARS5, $1240 \mathrm{kPa}, 15 \mathrm{~min})$. A saturated boric acid solution $(30 \mathrm{ml})$ was then added to the solution, which was heated with the microwave digestion system (690 kPa, $5 \mathrm{~min})$. The supernatant was filtered with a $0.2-\mu \mathrm{m}$ pore membrane filter. ${ }^{19}$ The filtrate solution was diluted to $100 \mathrm{ml}$ with $1.0 \mathrm{~mol} \mathrm{l}^{-1} \mathrm{HNO}_{3}$. Yttrium was added to all solutions at a constant concentration of $5 \mathrm{mg} \mathrm{l}^{-1}$ as an internal standard. The solution was then measured by ICP-AES (Shimadzu, ICP-8000 or Thermo ELECTRON, IRIS Intrepid). According to a previous study, ${ }^{19}$ the recovery ratio of the microwave digestion was $92 \%$ (certified value of lead concentration was $10870 \mathrm{mg} \mathrm{kg}^{-1}$ ), and the relative standard deviation for the measurement $(n=8)$ was $3.0 \%$.

\section{Sequential extraction procedure}

Fly ash and known reference materials were fractionated into six fractions: a water soluble fraction, an ammonium acetate extractable fraction, an acid soluble fraction, a reducing extractable fraction, an oxidizing extractable fraction, and a residual fraction by the sequential extraction procedure. .12,13,16,17,20 $^{-1}$ Table 2 lists the steps involved in the sequential extraction procedure, where these fractions are referred to as Fr1 - Fr6, respectively. As mentioned above, the concentrations of the components in the extract solution were measured by ICP-AES.

Fractions from the sequential extraction procedure, which was originally designed for soil, do not necessarily correspond to the

Table 2 Protocol of sequential extraction procedure

\begin{tabular}{|c|c|c|c|c|c|}
\hline & \multirow{2}{*}{ Fraction } & \multicolumn{4}{|l|}{ Protocol } \\
\hline & & Reagent & $(L / S) / \mathrm{ml} \mathrm{g}^{-1}$ & Shaking/h & Temp. $^{\mathrm{a}}$ \\
\hline Fr1 & Water soluble & Ion exchange water & 10 & 6 & $\mathrm{rt}$ \\
\hline Fr2 & Ammonium acetate extractable & $1.0 \mathrm{~mol} \mathrm{l}^{-1} \mathrm{CH}_{3} \mathrm{COONH}_{4}$ & 10 & 6 & $\mathrm{rt}$ \\
\hline Fr3 & Acid soluble & $1.0 \mathrm{~mol} \mathrm{l}^{-1} \mathrm{CH}_{3} \mathrm{COONa}\left(\mathrm{pH} 5\right.$ with $\left.\mathrm{CH}_{3} \mathrm{COOH}\right)$ & 8 & 5 & $\mathrm{rt}$ \\
\hline Fr4 & Reducing extractable & $0.2 \mathrm{~mol} \mathrm{l}^{-1} \mathrm{NH}_{2} \mathrm{OH} \cdot \mathrm{HCl}$ (with $\mathrm{CH}_{3} \mathrm{COOH}$ in $25 \mathrm{vol} / \mathrm{vol} \%$ ) & 10 & 6 & $85^{\circ} \mathrm{C}$ \\
\hline \multirow{3}{*}{\multicolumn{2}{|c|}{ Fr5 Oxidizing extractable }} & $\begin{array}{l}\text { (1) } 30 \% \mathrm{H}_{2} \mathrm{O}_{2}\left(\mathrm{pH} 2 \text { with } \mathrm{HNO}_{3}\right) \\
0.02 \mathrm{~mol} \mathrm{l}^{-1} \mathrm{HNO}_{3}\end{array}$ & $\begin{array}{l}5 \\
3\end{array}$ & 2 & $85^{\circ} \mathrm{C}$ \\
\hline & & (2) $30 \% \mathrm{H}_{2} \mathrm{O}_{2}\left(\mathrm{pH} 2\right.$ with $\left.\mathrm{HNO}_{3}\right)$ & 3 & 3 & $85^{\circ} \mathrm{C}$ \\
\hline & & (3) $1.78 \mathrm{~mol} \mathrm{l}^{-1} \mathrm{CH}_{3} \mathrm{COONH}_{4}$ (with $\mathrm{CH}_{3} \mathrm{COOH}$ in $25 \mathrm{vol} / \mathrm{vol} \%$ ) & 9.66 & 0.5 & $\mathrm{rt}$ \\
\hline Fr6 & Residual & $\begin{array}{l}0.1 \mathrm{~g} \text { of sample is added to with } \mathrm{HNO}_{3}, \mathrm{HCl}, \mathrm{HF}(3 \mathrm{ml}, 2 \mathrm{ml}, 5 \mathrm{ml} \\
\text { each), and digested by microwave. After digestion, } 30 \mathrm{ml} \text { of } \\
\text { saturated boraic acid is added, and heated by microwave again. }\end{array}$ & & & \\
\hline
\end{tabular}

a. rt, room temperature. At the end of each step, sample was centrifuged and filtered. Then residue was dried at $105^{\circ} \mathrm{C}$ in $12 \mathrm{~h}$, and weighed.

Fr5 has 3 steps, and in this fraction, sample was cooled to room temperature between 2 nd and 3rd step. 
physicochemical nature of the chemical species. Therefore, reference materials were also fractionated by the sequential extraction procedure as controls. $\mathrm{SiO}_{2}$ was mixed with $5 \% \mathrm{w} / \mathrm{w}$ reagents of lead, and used as known reference materials. To prepare the reference materials, $\mathrm{Pb}, \mathrm{Pb}_{2} \mathrm{O}(\mathrm{OH})_{2}, \mathrm{PbS}, \mathrm{PbCO}_{3}$, $\mathrm{PbCl}_{2}, \mathrm{~Pb}_{3}\left(\mathrm{PO}_{4}\right)_{2}, \mathrm{PbHPO}_{4}$, chloropyromorphite $\left(\mathrm{Pb}_{5}\left(\mathrm{PO}_{4}\right)_{3} \mathrm{Cl}\right.$; $\mathrm{CP}), \mathrm{PbSiO}_{3}, \mathrm{~Pb}(\mathrm{OAc})_{2},\left(\mathrm{~Pb}\left(\mathrm{CH}_{3} \mathrm{COO}\right)_{2}\right), \mathrm{PbO}, \mathrm{Pb}_{3} \mathrm{O}_{4}, \mathrm{PbO}_{2}$, and $\mathrm{PbSO}_{4}$ were purchased from Soekawa Chemical Co., Ltd. (Tokyo, Japan), Nacalai Tesque Inc. (Kyoto, Japan), and Nichika Inc. (Kyoto, Japan).

\section{Cluster analysis}

Cluster analysis was conducted on the results of the sequential extraction procedure and XAFS fitting to classify the results. ${ }^{21}$ The origins of fly ash were then examined in relation to their classification. The cluster analysis was conducted using commercially available add-on software in Excel (Esumi Co., Ltd., Tokyo, Japan). The Euclidean distances between points were then calculated, and the distances between clusters were computed using Ward's method.

\section{XAFS experiments}

In preparing reference materials for XAFS experiments, reagents were mixed with boron nitride $(\mathrm{BN})$, such that the $S / N$ ratio of the spectrum was optimized; they were formed into pellets, and stored in sealed polyethylene bags. Fly ash was prepared by sealing the powder directly into polyethylene bags. XAFS measurements were carried out on beam line 01B1 of Spring-8 (Hyogo, Japan). Spectra were recorded in the fluorescence mode using a Lytle detector for fly-ash samples and in the transmission mode using an ionization chamber for reference materials with $\mathrm{Si}$ (111).

Both the XANES and EXAFS regions of samples were analyzed. The XANES spectra of reference materials were compared with those of fly ash to identify major species. It was assumed that the spectra of unknown species were expressed by the synthesized spectra of known reference species. Thus, the major species in fly ash was identified and quantified using the linear combination fit (LCF) technique, in which spectra of known reference species were fitted to the spectrum of an unknown sample. . $^{2,-10}$ We conducted the LCF of XANES using the commercial software REX 2000 Ver. 2.3.3 (Rigaku Co., Ltd.). To statistically determine the number of reference species, a principal component analysis (PCA) was conducted on XANES spectra from 13 kinds of fly ash.,22-26 PCA was conducted with commercially available add-on software in Excel (Esumi Co., Ltd.). It was assumed that each percentage of the total lead obtained by LCF of the XANES spectrum indicates the mole percentage. In XANES analysis, $13037.7 \mathrm{eV}$ is defined as the L3 absorption edge (the first inflection point) in lead metal foil.

The EXAFS spectra of reference materials were then compared with the spectral shapes of fly ash, while utilizing amplitudes and phases to identify the major species. ${ }^{26}$ We conducted the LCF of EXAFS using the data analysis software package SixPACK Ver. 0.68. ${ }^{27}$ We conducted PCA for 13 kinds of EXAFS spectra from unknown samples, as compared to their XANES spectra.

The residual value $(R)$, calculated using Eq. (1), was used to evaluate the LCF for the experimental spectra of both XANES and EXAFS.

$$
R=\frac{\sum\left(\mathrm{XAFS}_{\text {measd }}-\mathrm{XAFS}_{\text {calcd }}\right)^{2}}{\sum\left(\mathrm{XAFS}_{\text {measd }}\right)^{2}}
$$

Reference species for XAFS were the same as those used in the sequential extraction procedure.

\section{Leaching model}

Lead chemical species within the extract solution obtained from the sequential extraction procedure were estimated using a chemical equilibrium model calculation. The calculation was conducted using the chemical equilibrium model program Visual MINTEQ ver. 2.61.,28,29 The default values of Visual MINTEQ Ver. 2.61 were used over all parameters, such as the value of $\log K_{\text {sp. }}$. Furthermore, $\mathrm{Cl}^{-}$and $\mathrm{SO}_{4}{ }^{2-}$ within the extract solution was measured using ion chromatography (IC; DIONEX, ICS-3000). The input condition details, such as the kind of element, the chemical species, and their concentrations, were based on the results of the sequential extraction procedure and the XANES spectral fitting.

\section{Results and Discussion}

Characterization of, and the sequential extraction procedure for, fly ash

Table 3 lists the compositions of the various fly-ash samples used in this study. They consisted mainly of $\mathrm{Ca}, \mathrm{Cl}$, and $\mathrm{O}$; the concentration of lead ranged from 1100 to $30000 \mathrm{mg} \mathrm{kg}^{-1}$. Although variable, the fly ash used in this study is general. $3,19,21,30,31$ The results of the sequential extraction procedure for unknown fly ash samples and the $\mathrm{pH}$ of the extract solutions are shown in Fig. 1 and Table 4, respectively. Although the $\mathrm{pH}$ of the solvents used in the sequential extraction procedure had been adjusted (as shown in Table 2), the $\mathrm{pH}$ of the extract solution was greatly influenced by the sample matrix. In particular, the $\mathrm{pH}$ values in $\mathrm{Fr} 1$ were greatly affected by the sample matrix; the $\mathrm{pH}$ in this fraction ranged from 6.2 to 12.5 . A previous study ${ }^{21}$ of fly ash reported that, in the sequential extraction procedure, Fr4 had the highest fraction ratios, Fr3 or Fr5 had the second-highest fraction ratios, and Fr1 of some samples had ratios in excess of $20 \%$. Our results are in agreement with this study.

The results of a cluster analysis of fraction ratios obtained by the sequential extraction procedure are shown in a dendrogram in Fig. 2. Three clusters were obtained from the dendrogram: $\mathrm{X} 1, \mathrm{X} 2$, and $\mathrm{X} 3$. The relation between these clusters and the specifications of samples are compared in Table 1. Except for fly-ash A, the fly ashes in cluster X1 were molten fly ash, formed from the melting process of bottom ash or fly ash; their Fr1 and Fr4 fraction ratios were high. Except for fly ash I, the fly ashes in cluster X2 were MSWI fly ash with high Fr3 and Fr4 fraction ratios. The fly ashes in cluster X3 comprised molten fly ash with high fraction ratios of Fr5 and Fr6. These results show that fly ash classified as X1 eluted easily, that classified as X2 was somewhat eluted, and X3 fly ash was hardly eluted. Thus, it was assumed that the results of the sequential extraction procedure were related to the manner in which different fly ashes were produced. However, while it was expected that differences in the flue gas treatment systems (lime and activated carbon) would influence the results of the sequential extraction procedure, cluster analysis revealed no clear tendency as to the flue gas treatment systems. Table 4 along with Fig. 2 show that $\mathrm{X} 1$ fly ash had high $\mathrm{pH}$ values in Fr1, from 12.0 to 12.4 , and with the exception of B, X2 fly ash had $\mathrm{pH}$ values of 9.6-11.8 in Fr1. Thus, it was assumed that the results of the sequential extraction procedure were greatly influenced by the $\mathrm{pH}$. 
Table 3 Chemical compositions of samples

\begin{tabular}{|c|c|c|c|c|c|c|c|c|c|c|c|c|c|c|}
\hline Sample & A & B & $\mathrm{C}$ & $\mathrm{D}$ & $\mathrm{E}$ & $\mathrm{F}$ & G & $\mathrm{H}$ & I & $\mathrm{J}$ & $\mathrm{K}$ & $\mathrm{L}$ & M & Unit \\
\hline $\mathrm{Cd}$ & 360 & 58 & 180 & 470 & 310 & 44 & 120 & 210 & 130 & 130 & 480 & 390 & 330 & $\mathrm{mg} \mathrm{kg}^{-1}$ \\
\hline $\mathrm{Cr}$ & 130 & 160 & 120 & 110 & 440 & 570 & 150 & ND & 65 & ND & ND & ND & ND & \\
\hline $\mathrm{Cu}$ & 310 & 540 & 480 & 1400 & 1400 & 5000 & 7800 & 2300 & 16000 & 2400 & 1000 & 920 & 850 & \\
\hline $\mathrm{Fe}$ & 9800 & 9600 & 8300 & 10000 & 6000 & 18000 & 18000 & 2000 & 13000 & 900 & 2500 & 1800 & 1500 & \\
\hline $\mathrm{Mg}$ & 4200 & 18000 & 6700 & 9800 & 9200 & 25000 & 11000 & 1200 & 3100 & 2500 & 810 & 600 & 2300 & \\
\hline $\mathrm{Mn}$ & 860 & 450 & 320 & 800 & 620 & 3000 & 910 & 100 & 150 & ND & ND & ND & ND & \\
\hline $\mathrm{P}$ & 2500 & 4700 & 6600 & 5600 & 5300 & 25000 & 1600 & 1200 & 920 & 580 & 760 & 25000 & 14000 & \\
\hline $\mathrm{Pb}$ & 6600 & 1100 & 1100 & 5000 & 4900 & 2900 & 16000 & 13000 & 19000 & 16000 & 7800 & 30000 & 18000 & \\
\hline $\mathrm{Ti}$ & 580 & 8700 & 6700 & 11000 & 8000 & 31000 & 1700 & 160 & 260 & 390 & 150 & 110 & 610 & \\
\hline $\mathrm{Zn}$ & 14000 & 9100 & 6600 & 24000 & 21000 & 9500 & 74000 & 35000 & 49000 & 53000 & 38000 & 130000 & 89000 & \\
\hline $\mathrm{Ca}$ & 32 & 19 & 18 & 9.8 & 17 & 16 & 15 & 8.5 & 29 & 29 & 20 & 4.9 & 7.6 & wt $\%$ \\
\hline $\mathrm{Cl}$ & 20 & 23 & 25 & 16 & 15 & 11 & 4.3 & 34 & 28 & 14 & 27 & 23 & 24 & \\
\hline $\mathrm{K}$ & 5.1 & 9.6 & 11 & 4.6 & 8.1 & 9.5 & 9.9 & 15 & 6.5 & 3.3 & 8.8 & 12 & 11 & \\
\hline $\mathrm{Na}$ & 3.6 & 10 & 6.5 & 9.0 & 7.0 & 4.1 & 6.2 & 17 & 5.4 & 2.9 & 10 & 11 & 12 & \\
\hline $\mathrm{O}$ & 30 & 15 & 18 & 20 & 21 & 25 & 14 & 18 & 15 & 40 & 24 & 24 & 23 & \\
\hline S & 1.6 & 2.3 & 1.6 & 2.8 & 2.7 & 1.6 & 1.4 & 1.4 & 0.84 & 1.7 & 2.0 & 1.4 & 0.42 & \\
\hline $\mathrm{Si}$ & 1.7 & 3.5 & 6.6 & 5.5 & 2.0 & 10 & 2.9 & 0.43 & 0.43 & 0.26 & 1.5 & 1.3 & 3.3 & \\
\hline
\end{tabular}

The Cl, O, S, and Si concentrations were determined by XRF spectroscopy. Other elements were measured by ICP-AES.

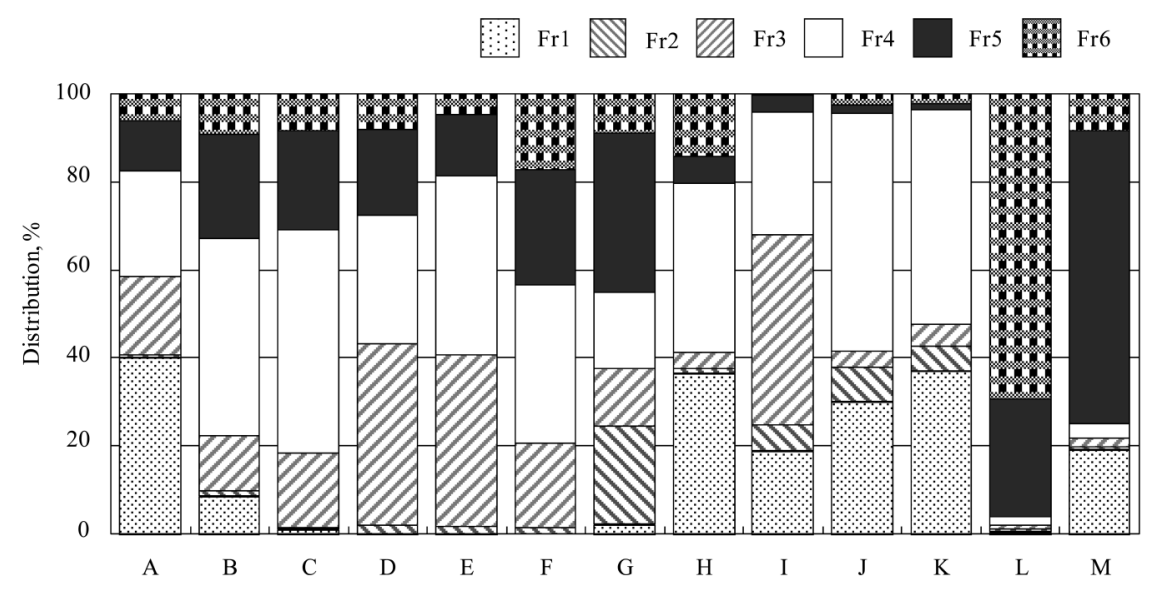

Fig. 1 Lead distributions of a sample by the sequential extraction procedure.

Table $4 \mathrm{pH}$ value at each step in the sequential extraction procedure for sample fly ash

\begin{tabular}{|c|c|c|c|c|c|c|c|c|c|c|c|c|c|}
\hline & A & B & $\mathrm{C}$ & $\mathrm{D}$ & $\mathrm{E}$ & $\mathrm{F}$ & $\mathrm{G}$ & $\mathrm{H}$ & I & $\mathrm{J}$ & $\mathrm{K}$ & $\mathrm{L}$ & M \\
\hline Fr1 & 12.0 & 12.3 & 11.8 & 10.7 & 10.4 & 9.6 & 6.2 & 12.4 & 11.8 & 12.3 & 12.2 & 10.6 & 12.5 \\
\hline Fr2 & 9.6 & 9.6 & 9.3 & 9.0 & 9.1 & 8.9 & 7.3 & 8.9 & 8.2 & 10.9 & 10.4 & 8 & 8.5 \\
\hline Fr3 & 7.0 & 6.0 & 6.4 & 5.8 & 5.9 & 5.8 & 6.7 & 7.5 & 6.6 & 7.9 & 7.6 & 6.3 & 6.9 \\
\hline Fr4 & 3.4 & 3.6 & 3.2 & 3.5 & 3.3 & 3.1 & 3.2 & 3.9 & 3.5 & 4.1 & 4 & 3.7 & 3.7 \\
\hline Fr5 & 2.0 & 1.5 & 1.1 & 1.4 & 1.4 & 1.3 & 1.4 & 0.8 & 0.6 & 1.1 & 1.1 & 1.8 & 1.4 \\
\hline Fr6 & - & - & - & - & - & - & - & - & - & - & - & - & - \\
\hline
\end{tabular}

Sequential extraction procedure for the reference materials

The results of the sequential extraction procedure for known reference materials and the $\mathrm{pH}$ of extract solutions are shown in Fig. 3 and Table 5, respectively. More than $90 \%$ of all $\mathrm{Pb}(\mathrm{OAc})_{2}$, $\mathrm{PbO}, \mathrm{PbHPO}_{4}, \mathrm{~Pb}_{3}\left(\mathrm{PO}_{4}\right)_{2}$, and $\mathrm{CP}$ were extracted in one fraction in the sequential extraction procedure. Thus, these lead species were estimated to have high extraction selectivity in each fraction in the sequential extraction procedure. On the other hand, the other lead species was extracted in three or more fractions. For instance, if the lead in fly ash is extracted in two fractions of Fr1 and Fr2, it is suggested that there are four or fewer lead species: $\left(\mathrm{Pb}(\mathrm{OAc})_{2}, \mathrm{PbCl}_{2}, \mathrm{~Pb}_{2} \mathrm{O}(\mathrm{OH})_{2}\right.$, or $\left.\mathrm{PbO}\right)$ (Fig. 3). As shown in Fig. 1, the lead in fly ash was extracted in three or more fractions; none were extracted in one or two fractions. Consequently, it was extremely difficult to estimate the ratio of the lead species based on the fraction ratio obtained from the sequential extraction procedure.

\section{XAFS analysis of fly ash}

The XANES spectra of fly ash and reference materials are shown in Fig. 4. The shapes of the XANES spectra of reference materials were compared to those of fly ash. PCA of the 13 
XANES spectra showed that the first, second, third, and fourth components were responsible for $43,23,16$, and $9 \%$ of the variance, respectively. The cumulative contribution ratio of the four components was $90 \%$, suggesting that there are four or fewer major chemical lead species in the fly ash.?

Regarding the shape of the XANES spectra, the fly ashes were classified roughly into three groups: (1) those that had a sharp absorption edge peak around at $13055 \mathrm{eV}$ (fly ashes A, B, H, I, $\mathrm{J}$, and $\mathrm{K}$ ); (2) those with a flat absorption edge peak (fly ashes E, F, and G); and (3) all others (fly ashes C, D, L, and M). Table 6 shows the results of XANES fitting of synthesized spectra of known references to those of fly ash. The synthesized

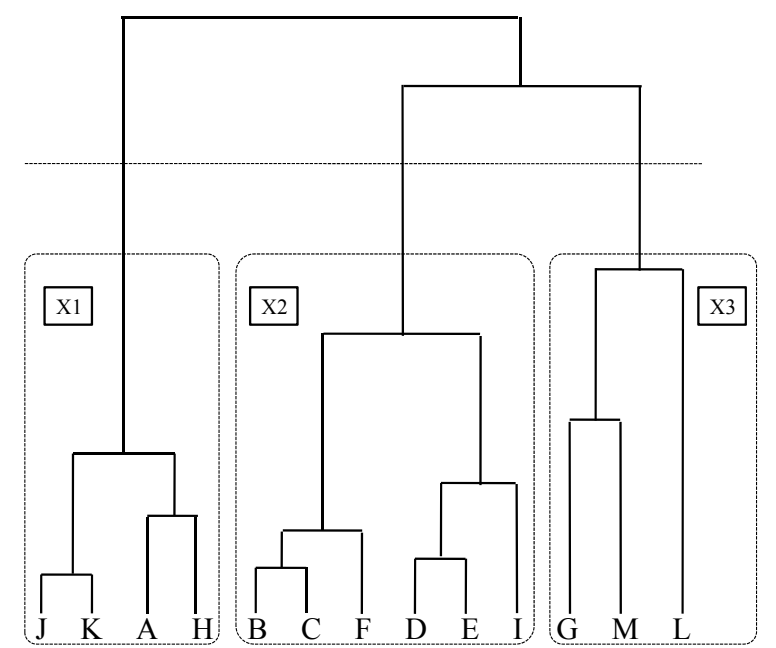

Fig. 2 Dendrogram based on the result of the sequential extraction procedure.

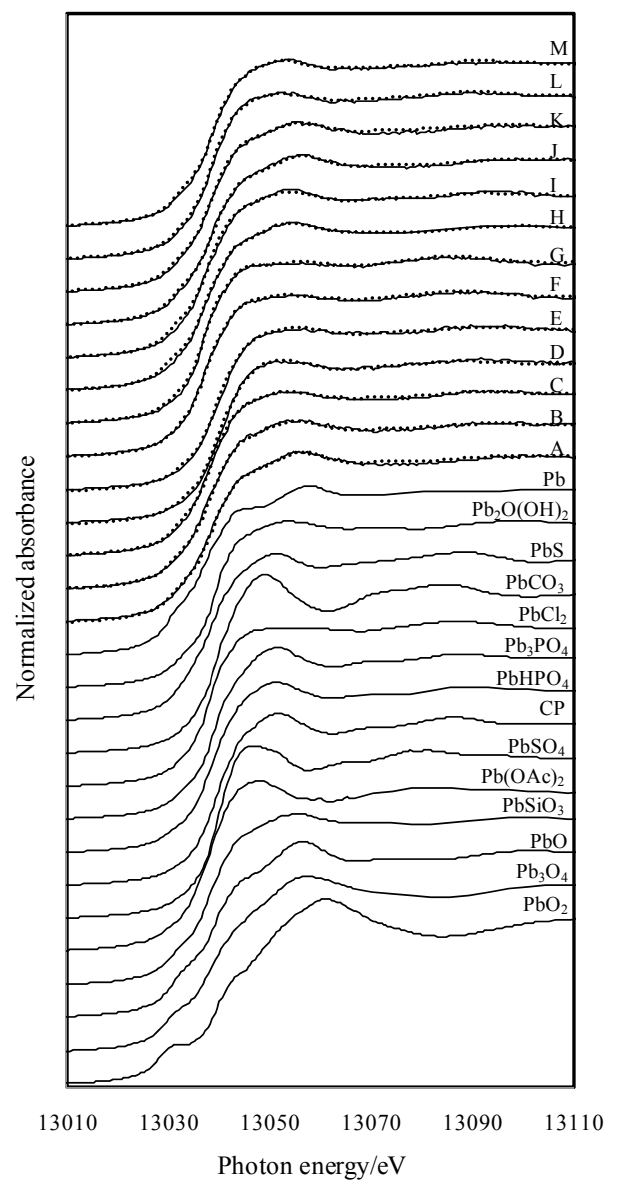

Fig. 4 Lead L3 edge XANES spectra of reference materials and fly-ash samples (solid lines). Dashed lines overlapped on solid lines show simulation spectra.

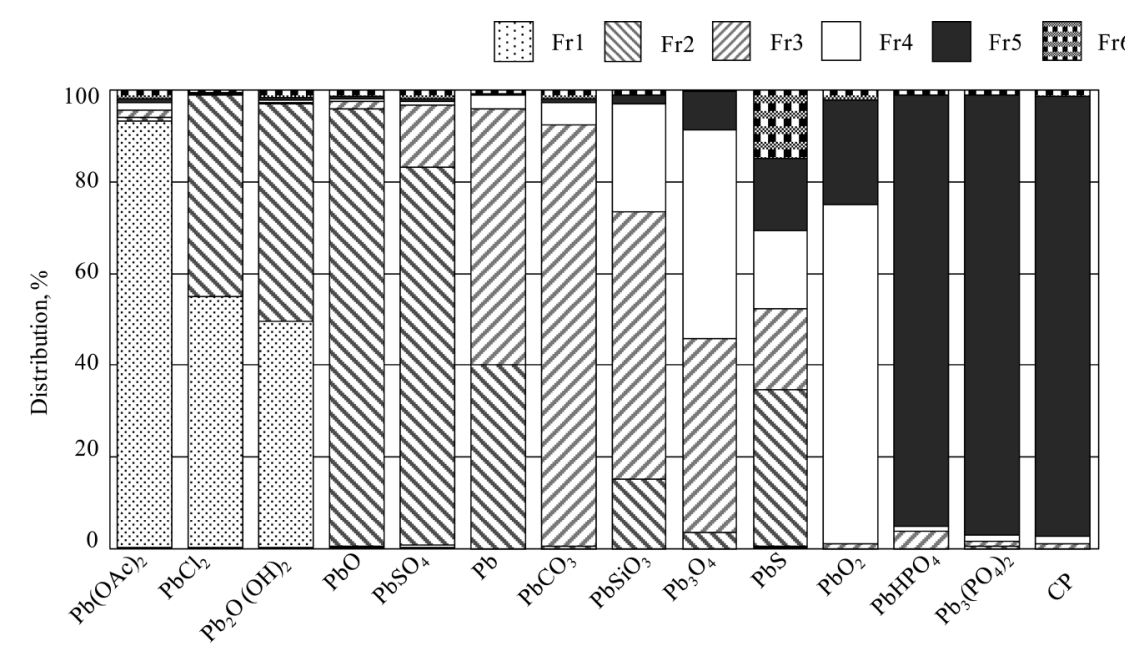

Fig. 3 Lead distributions of reference materials by the sequential extraction procedure.

Table $5 \mathrm{pH}$ value at each step of the sequential extraction procedure for reference materials

\begin{tabular}{ccccccccccccccc}
\hline & $\mathrm{Pb}(\mathrm{OAc})_{2}$ & $\mathrm{PbCl}_{2}$ & $\mathrm{~Pb}_{2} \mathrm{O}(\mathrm{OH})_{2}$ & \multicolumn{1}{c}{$\mathrm{PbO}$} & $\mathrm{PbSO}_{4}$ & \multicolumn{1}{c}{$\mathrm{Pb}$} & $\mathrm{PbCO}_{3}$ & $\mathrm{PbSiO}_{3}$ & $\mathrm{~Pb}_{3} \mathrm{O}_{4}$ & $\mathrm{PbS}$ & $\mathrm{PbO}_{2}$ & $\mathrm{PbHPO}_{4}$ & $\mathrm{~Pb}_{3}\left(\mathrm{PO}_{4}\right)_{2}$ & $\mathrm{CP}^{2}$ \\
\hline Fr1 & 6.1 & 4.9 & 6.8 & 10.0 & 7.0 & 10.5 & 6.8 & 8.3 & 6.6 & 7.0 & 8.3 & 4.1 & 4.1 & 6.9 \\
$\mathrm{Fr} 2$ & 7.1 & 7.1 & 7.3 & 8.1 & 7.1 & 8.2 & 7.8 & 7.7 & 7.3 & 7.2 & 7.1 & 7.0 & 6.7 & 7.8 \\
$\mathrm{Fr} 3$ & 5.0 & 5.0 & 5.1 & 5.1 & 5.1 & 5.1 & 5.3 & 5.4 & 5.3 & 5.1 & 5.0 & 5.3 & 5.3 & 5.2 \\
$\mathrm{Fr} 4$ & 1.8 & 1.9 & 1.9 & 2.0 & 1.9 & 1.9 & 2.0 & 2.0 & 2.3 & 2.0 & 2.1 & 1.9 & 1.9 & 1.8 \\
Fr5 & 0.3 & 0.3 & 0.3 & 0.4 & 0.4 & 0.3 & 0.2 & 0.3 & 0.5 & 0.3 & 0.3 & 0.2 & 0.3 & 0.4 \\
Fr6 & - & - & - & - & - & - & - & - & - & - & - & - & - & - \\
\hline
\end{tabular}


Table 6 Results of XANES fittings of sample (\%)

\begin{tabular}{ccccccccc}
\hline Sample & $R$ & $\mathrm{PbSiO}_{3}$ & $\mathrm{PbCl}_{2}$ & $\mathrm{PbO}$ & $\mathrm{Pb}$ & $\mathrm{PbS}$ & $\mathrm{Pb}_{2} \mathrm{O}(\mathrm{OH})_{2}$ & $\mathrm{PbCO}_{3}$ \\
\hline $\mathrm{A}$ & 0.009 & 48 & 17 & 21 & 15 & & & \\
$\mathrm{~B}$ & 0.008 & 48 & 23 & 18 & & 10 & & \\
$\mathrm{C}$ & 0.006 & 32 & 21 & & 14 & 33 & \\
$\mathrm{D}$ & 0.010 & 49 & 22 & & & & & 29 \\
$\mathrm{E}$ & 0.009 & 54 & 35 & & & & & 11 \\
$\mathrm{~F}$ & 0.007 & 21 & 62 & & & 17 & & \\
$\mathrm{G}$ & 0.008 & & 90 & & 10 & & & \\
$\mathrm{H}$ & 0.007 & 88 & & & & & 12 & \\
$\mathrm{I}$ & 0.009 & & 24 & 27 & & 18 & 30 & \\
$\mathrm{~J}$ & 0.007 & 52 & 15 & 21 & 12 & & & \\
$\mathrm{~K}$ & 0.008 & 51 & 28 & 10 & 11 & & & \\
$\mathrm{~L}$ & 0.007 & & 32 & & & 25 & 43 & \\
$\mathrm{M}$ & 0.006 & 20 & & & & 36 & 44 & \\
\hline
\end{tabular}

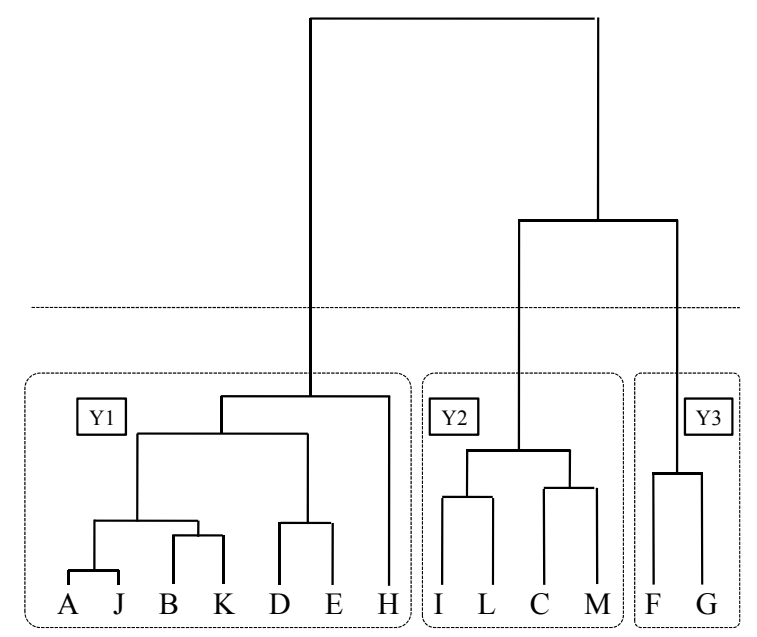

Fig. 5 Dendrogram based on the result of an XANES fitting.

spectra are shown as a dashed line on the XANES spectra of fly ash in Fig. 4. The $R$ values for all samples were $\leq 0.010$, indicating satisfactory fits. Previous studies ${ }^{9,32}$ reported that $\mathrm{PbCl}_{2}$, or $\mathrm{PbO}$ is the predominant form of lead in fly ash when $\mathrm{PbSiO}_{3}$ is not used as a reference material. The results of a cluster analysis of the XANES fitting are shown in a dendrogram in Fig. 5. Three clusters were obtained from the dendrogram: clusters Y1 (A, B, D, E, H, J, and K), Y2 (C, I, L, and M), and $\mathrm{Y} 3$ ( $\mathrm{F}$ and $\mathrm{G})$. $\mathrm{Y} 1, \mathrm{Y} 2$, and $\mathrm{Y} 3$ consisted mainly of $\mathrm{PbSiO}_{3}$, $\mathrm{Pb}_{2} \mathrm{O}(\mathrm{OH})_{2}$, and $\mathrm{PbCl}_{2}$, respectively. These classifications obtained from the XANES fitting are dissimilar to that obtained from the sequential extraction procedure, and do not appear to be related to the origins of the fly ash. As previously mentioned, it was assumed that the results of the sequential extraction procedure were more influenced by the $\mathrm{pH}$ than by the chemical species.

The $k^{3}$-weighted EXAFS spectra from both samples and the reference materials are shown in Fig. 6. The $k^{3}$-weighted EXAFS spectra of fly ash were smoothed by the Savitzky-Golay method (three smoothing points; one smoothing time). The EXAFS spectra became noisier above $6 \AA^{-1}$ for the fly-ash samples. PCA showed that for the 13 EXAFS spectra of fly ash in the range of 2 to $6 \AA^{-1}$, the first, second, third, and fourth components were responsible for $62,18,7$, and $5 \%$ of the variance, respectively. The cumulative contribution ratio of the four components was $92 \%$, suggesting that the lead in the fly

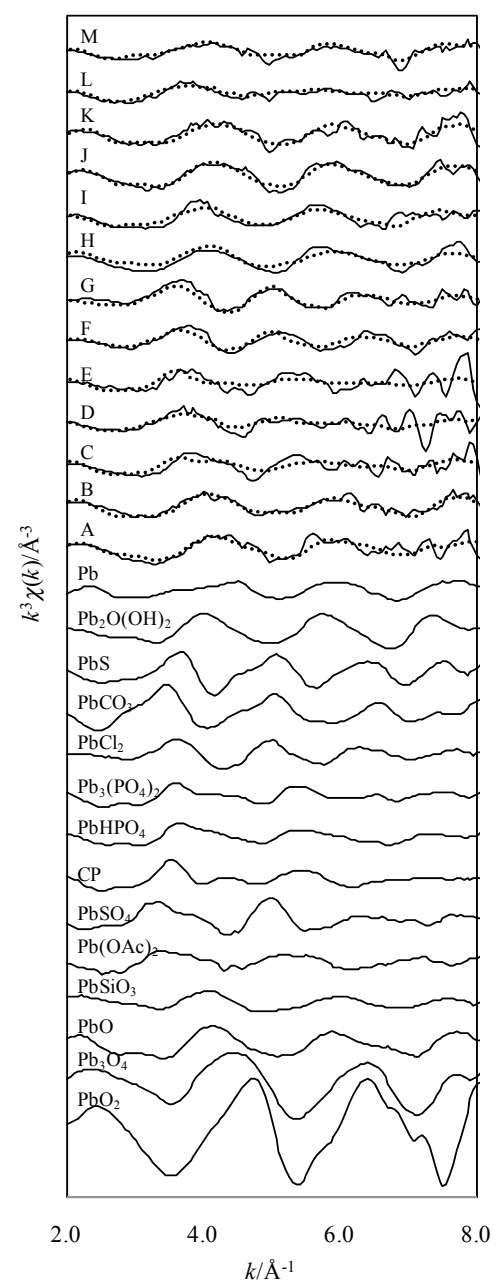

Fig. $6 \quad k^{3}$-Weighted EXAFS spectra of reference materials and fly ash samples.

ash consisted of four or fewer major species, similar to the XANES spectra results. We conducted the LCF of EXAFS in the range of 2 to $8 \AA^{-1}$. Table 7 gives the results of an EXAFS fitting of synthesized spectra of known references to those of fly ash. The synthesized spectra are shown as a dashed line on the EXAFS spectra of fly ash in Fig. 6. The results of a cluster analysis of the EXAFS fitting are shown in a dendrogram in Fig. 7. Two clusters were obtained from the dendrogram: clusters $\mathrm{Z1}$ (A - E and $\mathrm{H}-\mathrm{M}$ ) and $\mathrm{Z} 2$ (F and $\mathrm{G}) . \quad R$ values for all samples were in range 0.13 to 0.73 , indicating unsatisfactory fits. The result of an EXAFS fitting of most samples contained $\mathrm{CP}, \mathrm{PbHPO}_{4}$, and/or $\mathrm{Pb}_{3}\left(\mathrm{PO}_{4}\right)_{2}$, which was not reasonable thermodynamically in the view of the formation of fly ash. Though the result of EXAFS of fly ash D, I, and L contain CP, $\mathrm{PbHPO}_{4}$, and/or $\mathrm{Pb}_{3}\left(\mathrm{PO}_{4}\right)_{2}$ at 55, 48, 57\%, respectively, the result of the sequential extraction of those had the ratio of Fr5 was $19,4,27 \%$, respectively. There was a noticeable division between them. Additionally, the result of the EXAFS fitting disagrees with previous studies., ${ }^{9,31}$ In the classification of EXAFS fitting and XANES fitting, the cluster Z2 had same member as cluster Y3 (F and G), and fly ash belonging to Z1 could not be classified more fully. Therefore, we concluded that it was difficult to quantitatively examine the chemical species using only EXAFS, and quality of EXAFS spectra should be improved. 
Table 7 Results of EXAFS fittings of sample (\%)

\begin{tabular}{|c|c|c|c|c|c|c|c|c|c|c|c|c|c|}
\hline Sample & $R$ & $\mathrm{PbO}$ & $\mathrm{PbCl}_{2}$ & $\mathrm{~Pb}_{2} \mathrm{O}(\mathrm{OH})_{2}$ & $\mathrm{CP}$ & $\mathrm{PbHPO}_{4}$ & $\mathrm{~Pb}_{3}\left(\mathrm{PO}_{4}\right)_{2}$ & $\mathrm{~Pb}(\mathrm{OAc})_{2}$ & $\mathrm{PbSO}_{4}$ & $\mathrm{~Pb}$ & $\mathrm{PbO}_{2}$ & $\mathrm{PbSiO}_{3}$ & $\mathrm{PbCO}_{3}$ \\
\hline A & 0.32 & 41 & & 33 & 15 & & & & & & 10 & & \\
\hline B & 0.21 & 64 & 14 & & & 21 & & & & & & & \\
\hline $\mathrm{C}$ & 0.57 & 33 & 10 & & 32 & & 25 & & & & & & \\
\hline $\mathrm{D}$ & 0.59 & 12 & & & & 55 & & & 34 & & & & \\
\hline $\mathrm{E}$ & 0.73 & 15 & 27 & & 38 & & 19 & & & & & & \\
\hline $\mathrm{F}$ & 0.32 & 14 & 72 & & & & & 14 & & & & & \\
\hline $\mathrm{G}$ & 0.22 & & 63 & & & & 16 & & 21 & & & & \\
\hline $\mathrm{H}$ & 0.19 & 25 & & & & 25 & & & & & & 50 & \\
\hline I & 0.27 & 18 & & 34 & & & 32 & 16 & & & & & \\
\hline $\mathrm{J}$ & 0.13 & 50 & & 20 & & & & & & 31 & & & \\
\hline $\mathrm{K}$ & 0.31 & 48 & & & & & & & & 52 & & & \\
\hline $\mathrm{L}$ & 0.32 & 28 & 16 & & & & 21 & 36 & & & & & \\
\hline M & 0.25 & 34 & & 40 & & & & & & & & & 25 \\
\hline
\end{tabular}

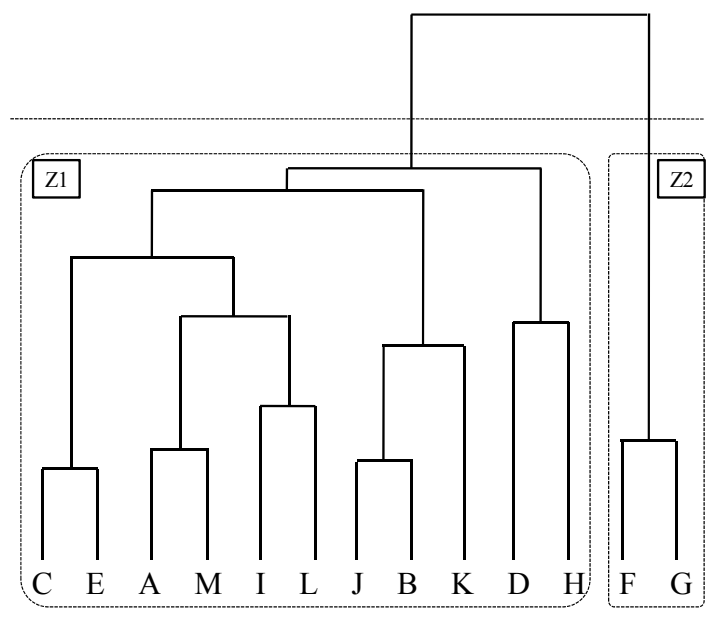

Fig. 7 Dendrogram based on the result of an EXAFS fitting.

XAFS analysis of the sequential extraction procedure residues of fly $\operatorname{ash} A$

Fly ash A was typical of MSWI fly ash in Japan, collected from stoker-type incinerators with a bug filter and lime processing. Because the lead concentration in A was greater than those in B and C, which were also typical fly ash, it should be easier to observe the chemical species in A using the sequential extraction procedure than in B or C. Therefore, A was used for estimating the chemical species by the sequential extraction procedure. XAFS analysis was performed on the Fr1, $\mathrm{Fr} 2$, and Fr3 residues from fly ash A. We called these residues A1, A2, and A3, respectively. The fractions were compared before and after extraction; these, as well as the XANES spectra of fly ash $\mathrm{A}$ and the residues of the sequential extraction procedure, are shown in Fig. 8. As mentioned above, the XANES spectrum of fly ash A was similar to that of $\mathrm{PbO}$ or $\mathrm{PbSiO}_{3}$. A1 was roughly similar to $\mathrm{A}$, but the spectral shape of A1 was more linear in the $13040-13054 \mathrm{eV}$ range than that of A. A2 was similar to $\mathrm{Pb}_{2} \mathrm{O}(\mathrm{OH})_{2}$. The absorption edge peak position of $\mathrm{A} 3$ did not differ much from that of $\mathrm{A} 2$, but the spectral shape was more distinctive. Table 8 gives the results of XANES fittings of synthesized spectra of known references along with the residues of the sequential extraction procedure; the ratios of chemical species when the lead contained in A is normalized to $100 \%$ are given in parentheses. For example, $40 \%$ was extracted from fly ash A in Fr1, with a total ratio of

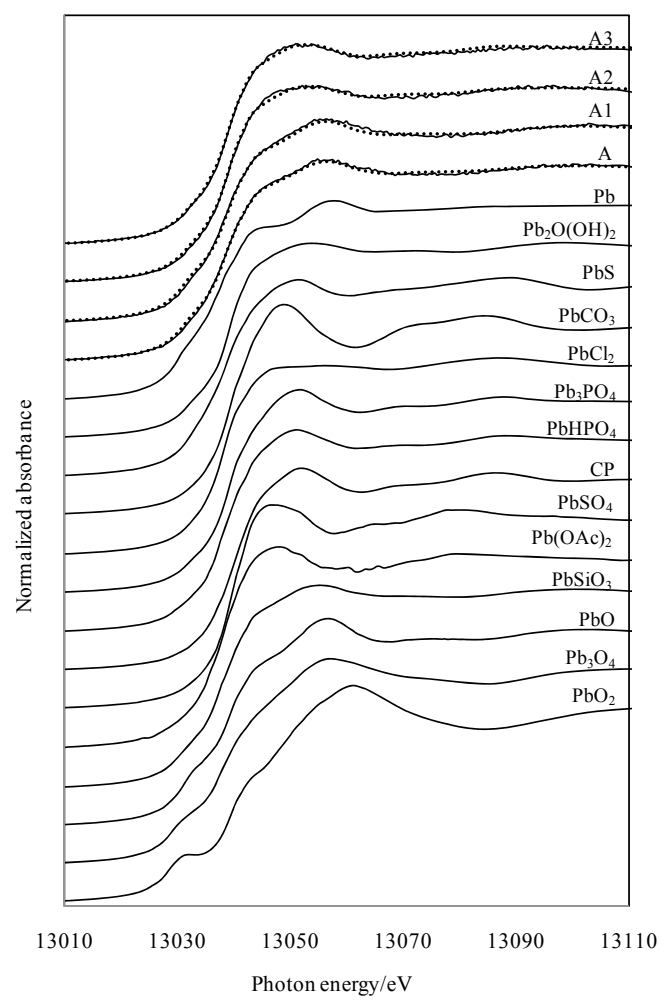

Fig. 8 Lead L3 edge XANES spectra of reference materials, fly ash $\mathrm{A}$, and residues of sequential extraction procedure (solid lines). Dashed lines overlapped on solid lines show simulation spectra.

A1 of $60 \%(100 \%-40 \%=60 \%)$; thus, the total ratio of chemical species contained in A1 is $60 \%(60 \%=28 \%+16 \%+$ $9 \%+7 \%)$. Synthesized spectra are shown in Fig. 8 as dashed lines on the XANES spectra of residues obtained from the sequential extraction procedure. The $R$ values calculated for all fly ashes were $\leq 0.009$, indicating satisfactory fits. These results suggest that most $\mathrm{PbCl}_{2}$ and a portion of $\mathrm{PbO}$ and $\mathrm{PbSiO}_{3}$, are dissolved in Fr1, and are subsequently partially re-precipitated as hydroxide. The authors' research group has confirmed that both $\mathrm{PbSiO}_{3}$ and $\mathrm{PbO}$ are dissolved under alkaline conditions. The ratio of hydroxide in A2 was greater than that in A1. This result is not reasonable, given that the product contains $\mathrm{PbS}$, which cannot be generated by re-precipitation. When $\mathrm{PbS}$ was excluded from the spectral fitting of A2, CP made up $27 \%$ of $\mathrm{A} 2$ 
Table 8 Results of XANES fittings of synthesized spectra of known references with the residues of the sequential extraction procedure (\%)

\begin{tabular}{|c|c|c|c|c|c|c|c|c|}
\hline Sample & $R$ & $\mathrm{PbSiO}_{3}$ & $\mathrm{PbCl}_{2}$ & $\mathrm{PbO}$ & $\mathrm{Pb}$ & $\mathrm{Pb}_{2} \mathrm{O}(\mathrm{OH})_{2}$ & $\mathrm{CP}$ & $\mathrm{PbS}$ \\
\hline A & 0.009 & 48 & 17 & 21 & 15 & & & \\
\hline A1 & 0.009 & $47(28)$ & & $26(16)$ & $15(9)$ & $12(7)$ & & \\
\hline \multirow[t]{2}{*}{$\mathrm{A} 2$} & 0.008 & & & & & 73 (44) & & 27 (16) \\
\hline & $0.009^{\mathrm{a}}$ & & & & $15(9)$ & $58(35)$ & $27(16)$ & \\
\hline \multirow[t]{2}{*}{$\mathrm{A} 1$} & 0.008 & & & & & $58(24)$ & $8(3)$ & 34 (14) \\
\hline & $0.009^{\mathrm{a}}$ & & & & $19(8)$ & $40(16)$ & $39(17)$ & \\
\hline
\end{tabular}

a. Fitting analysis for XANES is carried out without using $\mathrm{PbS}$ as reference species. The ratios of chemical species when the lead contained in $\mathrm{A}$ is normalized to $100 \%$ are given in parentheses.

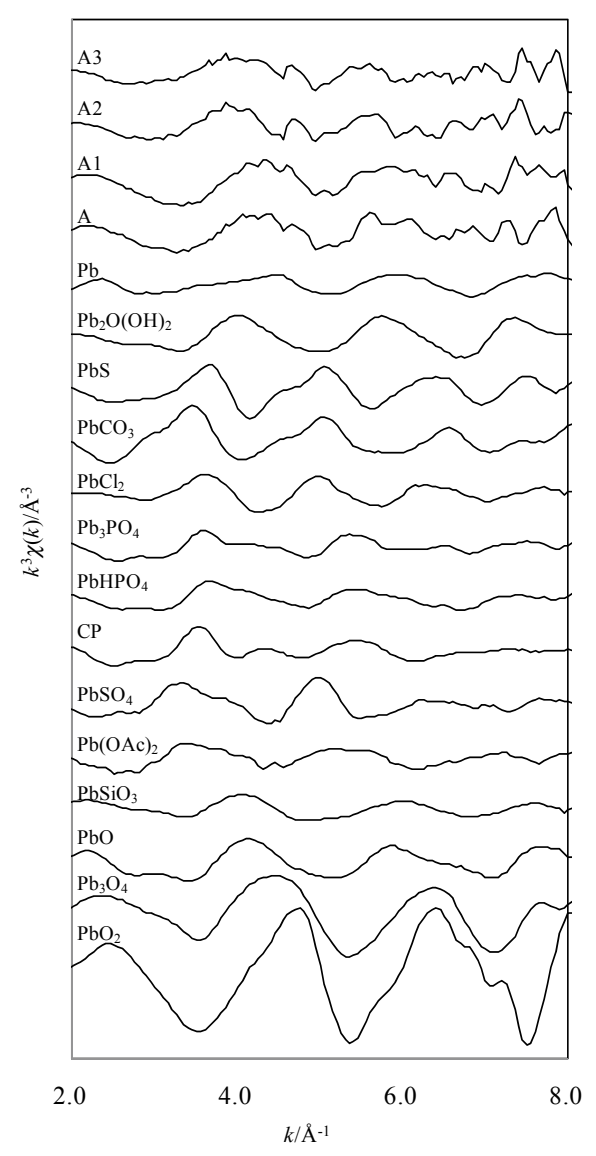

Fig. $9 k^{3}$-Weighted EXAFS spectra of reference materials, fly ash A, and residue of sequential extraction procedure.

(16\% when the lead level in A was normalized to $100 \%)$. When $\mathrm{PbS}$ was excluded from a spectral fitting of $\mathrm{A} 3, \mathrm{CP}$ comprised $27 \%$ of A3 (17\% when the lead level in A was normalized to $100 \%$ ). In past work, ${ }^{33}$ which aimed to stabilize heavy metals in MSWI bottom ash using soluble phosphate, XPS revealed that lead in bottom ash formed CP.

Figure 9 shows the $k^{3}$-weighted EXAFS spectra of residues obtained from the sequential extraction procedure. Both the XANES spectra and the EXAFS spectra of A1 and A2 changed despite little extraction in the sequential extraction procedure, suggesting that dissolved species re-precipitate in Fr2.

\section{Leaching behavior of $\mathrm{Frl}$ residue at various $\mathrm{pH}$ values}

The results of the XANES fitting and the sequential extraction of fly ash A suggest that $\mathrm{CP}$ is formed by re-precipitation in Fr2.
Table 9 Components concentrations input into Visual MINTEQ

\begin{tabular}{lc}
\hline Component & Concentration $/ \mathrm{mg}^{-1}$ \\
\hline $\mathrm{Al}^{3+}$ & 16 \\
$\mathrm{Ca}^{2+}$ & 13000 \\
$\mathrm{Cd}^{2+}$ & 42 \\
$\mathrm{Cl}^{-}$ & 380 \\
$\mathrm{Cu}^{2+}$ & 27 \\
$\mathrm{Fe}^{3+}$ & 2.0 \\
$\mathrm{~K}^{+}$ & 110 \\
$\mathrm{Mg}^{2+}$ & 1.2 \\
$\mathrm{Na}^{+}$ & 220 \\
$\mathrm{Zn}^{2+}$ & 1000 \\
$\mathrm{SO}_{4}^{2-}$ & 2200 \\
$\mathrm{CH}_{3} \mathrm{COO}^{-}$ & 59000 \\
$\mathrm{NH}_{4}{ }^{+}$ & 18000 \\
$\mathrm{~Pb}^{2+}$ & 520 \\
$\mathrm{PO}_{4}{ }^{3+}$ & 1200 \\
\hline
\end{tabular}

To confirm this, the chemical species in Fr2 residue of fly ash A were estimated using a chemical equilibrium model. The input conditions were based on the component concentrations in Fr2. Under these conditions, it was assumed that all phosphorus (P) existed as $\mathrm{PO}_{4}{ }^{3-}$, and could be dissolved at least once into solution in Fr2. Thus, all of the P contained in the Fr1 residue was used in the calculation $\left(\mathrm{PO}_{4}{ }^{3-}, 1200 \mathrm{mg} \mathrm{l}^{-1}\right)$. Additionally, all of the $\mathrm{PbSiO}_{3}, \mathrm{PbO}$, and $\mathrm{Pb}_{2} \mathrm{O}(\mathrm{OH})_{2}$ contained in the $\mathrm{Fr} 1$ residue was also used to calculate the composition $\left(\mathrm{Pb}^{2+}\right.$, $520 \mathrm{mg} \mathrm{l}^{-1}$ ), since it was assumed that these chemical species could precipitate with $\mathrm{PO}_{4}{ }^{3-}$ based on the result of XANES fittings of A1 and A2 (Table 8). Table 9 gives the input conditions. The $\mathrm{pH}$ was entered as a fixed value, ranging from 0.0 to 14.0. Oversaturated solutions were allowed to precipitate.

Figure 10 shows the results of a chemical equilibrium model simulation. Within the 2.0 to $7.0 \mathrm{pH}$ range, lead existed mainly as $\mathrm{CP}$, suggesting that it is precipitated as $\mathrm{CP}$ at a neutral $\mathrm{pH}$, in agreement with the simulations of previous studies. ${ }^{14,29}$ Meanwhile, CP could have extraction selectivity in Fr5, as shown in Fig. 3, and $11 \%$ was extracted in Fr5 in the sequential extraction procedure, as shown in Fig. 1. An XANES fitting produced a ratio of $\mathrm{CP}$ in $\mathrm{A} 3$ of $17 \%$ (Table 8), which did not completely agree with the result of the sequential extraction procedure; however, this makes sense if it is assumed that $\mathrm{CP}$, which was not originally contained in fly ash A, could be formed by re-precipitation.

\section{Influence of phosphorus concentration on extraction of Fr5}

Based on the high extraction selectivity of CP in Fr5, as well as the possibility that $\mathrm{CP}$ forms by re-precipitation, the impact of $\mathrm{P}$ concentration on the extraction of Fr5 was estimated. 


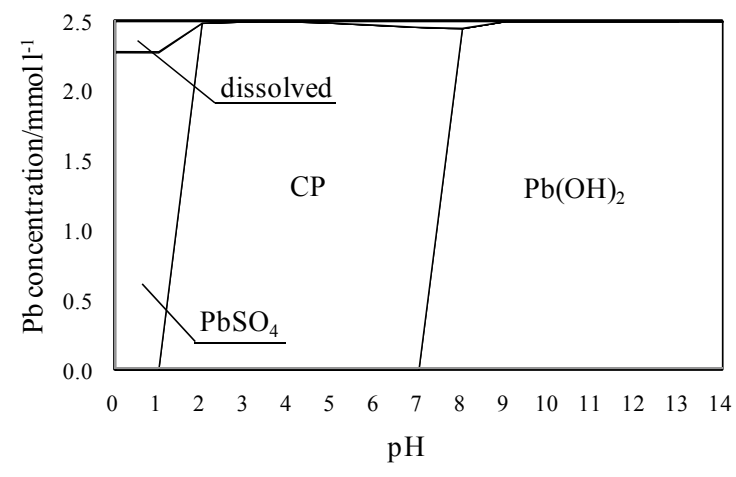

Fig. 10 Leaching diagram of lead in Fr2.

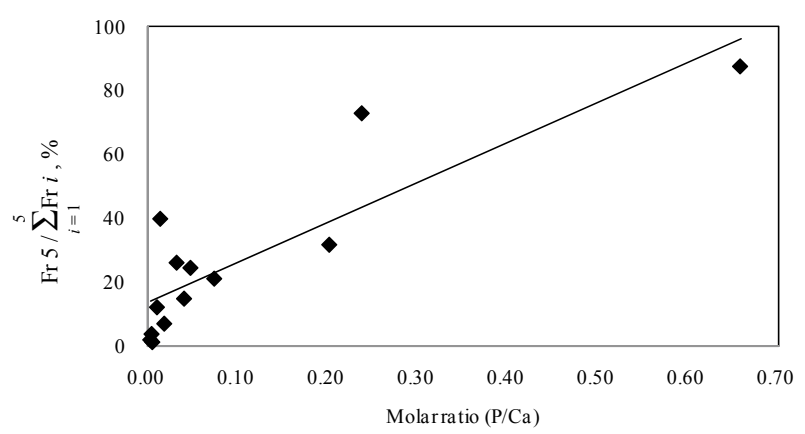

Fig. 11 Relation between the ratio of $\mathrm{P}$ to $\mathrm{Ca}$ in a sample and the ratio of Fr5 to the sum total from Fr1 to Fr5 obtained from the sequential extraction procedure $(y=126 x+13$, correlation coefficient $r=0.86)$

Two points in particular were noted: first, calcium could also form hydroxyapatite $\left(\mathrm{Ca}_{5}\left(\mathrm{PO}_{4}\right)_{3} \mathrm{OH}\right)$ with $\mathrm{PO}_{4}{ }^{3-}$ based on the results of the chemical equilibrium model; and second, what was extracted in Fr6 (after Fr5) did not influence re-precipitation before Fr5. There was a strong correlation (correlation coefficient $=0.86$ ) between the ratio of $\mathrm{P}$ to $\mathrm{Ca}$ concentrations and the ratio of Fr5 to Fr1-5, as shown in Fig. 11.

\section{Comparison of analysis methods}

The results of the sequential extraction procedure were more influenced by the $\mathrm{pH}$ than by the chemical species of lead. In this procedure, the chemical species of lead in fly ash may be estimated as shown below:

[Fr1] Both $\mathrm{PbCl}_{2}$ and $\mathrm{Pb}_{2} \mathrm{O}(\mathrm{OH})_{2}$ are dissolved. Under highly alkaline conditions, $\mathrm{PbSiO}_{3}, \mathrm{PbO}$, and a portion of $\mathrm{Pb}$ also dissolve, and re-precipitate partially as hydroxide. Under slightly alkaline or neutral conditions, most of the dissolved lead re-precipitates as hydroxide.

[Fr2 and $\mathrm{Fr} 3$ ] $\mathrm{Pb}, \mathrm{Pb}_{2} \mathrm{O}(\mathrm{OH})_{2}, \mathrm{PbCO}_{3}, \mathrm{PbO}$, and a portion of $\mathrm{PbS}$ dissolve. When the ratio of $\mathrm{P}$ to $\mathrm{Ca}$ contained in the fly ash is high, a portion of lead re-precipitates as CP.

[Fr4] All residual $\mathrm{PbSiO}_{3}$ and a portion of $\mathrm{PbS}$ dissolve.

[Fr5] All residual $\mathrm{PbS}$ and re-precipitated $\mathrm{CP}$ dissolve.

Based on the results of the sequential extraction procedure (Fig. 3), a portion of $\mathrm{PbS}$ is assumed to correspond to Fr6, which is not necessarily in line with the XANES fitting of fly ash L (Table 6).

In comparing the three methods (the sequential extraction procedure, XANES analysis, and EXAFS analysis), it is difficult to quantify the chemical species using the sequential extraction procedure, due to re-precipitation that occurs because of the fly-ash characteristics (e.g., $\mathrm{pH}$ and concentrations of $\mathrm{P}$ and $\mathrm{Ca}$ ). Thus, it is difficult to obtain accurate information reflecting the chemical species in fly ash using the sequential extraction procedure. On the other hand, this method is able to estimate the mobility potential of lead contained in fly ash. The EXAFS spectra were shown to be quite noisy. The shape of the EXAFS spectra could be used to roughly identify the chemical species; however, it was difficult to quantify these species. In using EXAFS analysis to quantify fly ash, the data measurement range maximum is $13460 \mathrm{eV}$, since the absorption edge of bromine appears after that of lead, causing interference. Consequently, it is difficult to quantitatively examine lead chemical species using EXAFS, because they exist at trace levels in fly ash. XANES was able to directly quantify the chemical species of lead contained in fly ash, without interference from sample matrices, and was therefore the most suitable method.

\section{Conclusion}

In this study, three methods were compared on the basis of their ability to quantify the chemical species of lead in fly ash. Of the three methods (the sequential extraction procedure, XANES analysis, and EXAFS analysis), it was observed that the results of the sequential extraction procedure were related to the material to process (ash or municipal solid waste) and the processing system, and thus did not reflect the chemical species in fly ash because of the influence of the $\mathrm{pH}$ and the sample matrix. It is also difficult to quantify the lead chemical species in fly ash using only EXAFS. The XANES method enabled the greatest degree of quantification of lead chemical species in fly ash. XANES analysis showed that lead in fly ash is mainly in the form of $\mathrm{PbSiO}_{3}, \mathrm{PbCl}_{2}$, or $\mathrm{Pb}_{2} \mathrm{O}(\mathrm{OH})_{2}$. The present study shows that the results of multiple analyses should be examined multilaterally to improve the accuracy of the final analysis. Additionally, it is important to ascertain whether a computational approach, such as the chemical equilibrium model simulation, is consistent with the analytical approach.

\section{References}

1. X. Wan, W. Wang, T. Ye, Y. Guo, and X. Gao, J. Hazard. Mater., 2006, 134, 197.

2. J. R. Kiser and B. A. Manning, J. Hazard. Mater., 2010 , 174, 167.

3. T. T. Eighmy, J. D. Eusden, Jr., D. S. Domingo, D. Stampfli, J. R. Martin, and P. M. Erickson, Environ. Sci. Technol., 1995, 29, 629.

4. A. Kida, Y. Noma, and T. Imada, Waste Manage., 1996, 16, 527.

5. M. Cobo, A. Galvez, J. A. Conesa, and C. M. Correa, J. Hazard. Mater., 2009, 168, 1223.

6. A. Manceau, M. C. Boisset, G. Sarret, J. L Hazemann, M. Mench, P. Cambier, and R. Prost, Environ. Sci. Technol., 1996, 30, 1540.

7. M. Takaoka, A. Shiono, K. Nishimura, T. Yamamoto, T. Uruga, N. Takeda, T. Tanaka, K. Oshita, T. Matsumoto, and H. Harada, Environ. Sci. Technol., 2005, 39, 5878.

8. M. Takaoka, T. Yamamoto, A. Shiono, N. Takeda, K. Oshita, T. Matsumoto, and T. Tanaka, Chemosphere, 2005, 59, 1497. 
9. M. Takaoka, T. Yamamoto, T. Tanaka, K. Oshita, and T. Uruga, Phys. Scr., 2005, T115, 943.

10. M. Takaoka, T. Fujimori, A. Shiono, T. Yamamoto, N. Takeda, K. Oshita, T. Uruga, Y. Sun, and T. Tanaka, Chemosphere, 2010, 80, 144.

11. Y. Nomura, K. Fujiwara, A. Terada, S. Nakai, and M. Hosomi, Waste Manage., 2010, 30, 1290.

12. M. L. Sammut, Y. Noack, J. Rose, J. L. Hazemann, O. Proux, M. Depoux, A. Ziebel, and E. Fiani, Chemosphere, 2010, 78, 445 .

13. V. Bruder-Hubscher, F. Lagarde, M. J. F. Leroy, C. Coughanowr, and F. Enguehard, Anal. Chim. Acta, 2002, $451,285$.

14. P. Van Herck, B. V. Bruggen, G. Vogels, and C. Vandecasteele, Waste Manage., 2000, 20, 203.

15. Z. Yan, J. Jianguo, and C. Maozhe, J. Environ. Sci., 2008, 20, 1398.

16. S. Abanades, G. Flamant, B. Gagnepain, and D. Gauthier, Waste Manage. Res., 2002, 20, 55.

17. D. Roberts, A. C. Scheinost, and D. L. Sparks, "Zinc Speciation in Contaminated Soils Combining Direct and Indirect Characterization Methods. In Geochemical and Hydrological Reactivity of Heavy Metals in Soils", ed. H. M. Selim and W. L. Kingery, 2003, Lewis Publishers, New York, 187.

18. Y. Izumi, M. Ogawa, S. Kato, J. Shiokawa, and T. Shiba, "Kikibunseki No Tebiki (in Japanese)", 1986, Kyoritsushuppan, Tokyo, 55.

19. M. Takaoka, D. Nakatsuka, N. Takeda, and T. Fujiwara,
J. Jpn. Soc. Waste Manage. Experts (in Japanese), 2000, $685,333$.

20. A. Tessier, P. G. C. Campbell, and M. Bisson, Anal. Chem., 1979, 51, 844 .

21. M. Takaoka, Y. Kuramoto, N. Takeda, and T. Fujiwara, Doboku Gakkai Ronbunshu (in Japanese), 2001, 685, 79.

22. E. R. Malinowski, Anal. Chem., 1977, 49, 606.

23. E. R. Malinowski, Anal. Chem., 1997, 49, 612.

24. S. Beauchemin, D. Hesterberg, and M. Beauchemin, Soil Sci. Soc. Am. J., 2002, 66, 83.

25. A. C. Scheinost, R. Kretzschmar, and S. Pfister, Environ. Sci. Technol., 2002, 36, 5021.

26. C. S. Kim, N. S. Bloom, J. J. Rytuba, and G. E. Brown, Jr., Environ. Sci. Technol., 2003, 37, 5102.

27. S. M. Webb, Phys. Scr., 2005, T115, 1011.

28. Y. Hashimoto, T. Taki, and T. Sato, J. Environ. Sci. Health, 2009, 44, 583.

29. B. V. Bruggen, G. Vogels, P. V Herck, and C. Vandecasteele, J. Hazard. Mater., 1998, 57, 127.

30. E. Fujimori, S. Iwata, K. Minamoto, K. Lee, A. Itoh, K. Chiba, and H. Haraguchi, Anal. Sci., 2004, 20, 189.

31. M. Torigai, T. Ouyang, K. Iwashima, M. Osako, and M. Tanaka, Bunseki Kagaku, 1997, 46, 401

32. Y. Nomura, K. Fujiwara, A. Terada, S. Nakai, and M. Hosomi, Waste Manage., 2010, 30, 1290.

33. B. S. Crannell, T. T. Eighmy, J. E. Krzanowski, J. D. Eusden, Jr., E. L. Shaw, and C. A. Francis, Waste Manage, 2000, 20, 135. 